\title{
Tight carbonate gas well deliverability evaluation and reasonable production proration analysis
}

\author{
Jiang $\mathrm{Li}^{1} \cdot$ Xianchao Chen ${ }^{1,2}(\mathbb{0}) \cdot$ Ping Gao ${ }^{1} \cdot$ Jingchao Zhou ${ }^{1}$
}

Received: 30 March 2021 / Accepted: 16 June 2021 / Published online: 3 July 2021

(c) The Author(s) 2021

\begin{abstract}
It is very important to accurately predict the gas well productivity and reasonably allocate the gas production at the early development stage of gas reservoirs. However, both the non-Darcy and stress sensitivity effects have not been investigated in dual-porosity model of tight carbonate gas reservoirs. This paper proposed a new dual-porosity binomial deliverability model and single-well production proration numerical model, which consider the effects of non-Darcy and stress sensitivity. The field gas well deliverability tests data validated the accuracy of the new analytical model, which is a very helpful deliverability method when lacking deliverability test. A geological model was built on the results of the well log, well testing, and well production analysis. Then, a reasonable production proration analysis was conducted based on history matched singlewell numerical model. The gas productivity index curve and production-prediction of MX22 several simulation cases were adopted to analyze the reasonable production proration. The results indicate that $1 / 6$ may be suitable for high productivity gas well proration. In addition, the absolute open flow rate from the numerical simulation is higher than that from the new deliverability equation, which also shows that the pressure transient analysis sometimes has some deviation in formation property prediction. It is suggested comprehensively utilizing the analytical binomial model and the single-well numerical model in tight carbonate gas well deliverability evaluation.
\end{abstract}

Keywords Tight carbonate gas well $\cdot$ Deliverability evaluation $\cdot$ Production proration $\cdot$ Non-Darcy $\cdot$ Stress sensitivity

\section{Introduction}

The development of tight carbonate gas reservoirs usually goes through three stages: early production building, middle stable yield, and late production decline. In early production stage, gas well deliverability evaluation and reasonable production proration analysis play an important role in reservoir production management (Jia, 2017). The tight carbonate Gaoshiti-Moxi gas reservoir, which is located in the middle of the Sichuan Basin, is just at the early production building stage (Wei, 2015). For carbonate gas reservoirs, complex natural fractures intensify the formation heterogeneity. The reservoir characteristics make it difficult to accurately

Xianchao Chen

chenxianchao2005@126.com; chenxianchao15@cdut.edu.cn

1 College of Energy Resources, Chengdu University of Technology, Sichuan, China

2 State Key Laboratory of Oil and Gas Reservoir Geology and Exploitation, (Chengdu University of Technology), Sichuan, China describe the gas flow of tight carbonate (Feng et al. 2019; Tan et al. 2021).

Both the non-Darcy and stress sensitivity effects are key in evaluating tight carbonate gas well productivity. Owing to the non-Darcy effect, the productivity index may be reduced up to $20 \%$ in a high rate gas well (Smith et al. 2004). The non-Darcy effect is still obvious even for low flow rate in the tight fractured reservoir or unconventional reservoir (Pereira et al. 2006). The stress sensitivity effect can also decrease the fracture permeability as the tight gas reservoir is depleting (Cho et al. 2013). It can not only affect the pressure transient analysis (Pedrosa Jr, 1986) but also damage the well productivity in sandstone or shale gas reservoirs (Deng et al. 2013; Yang et al. 2008).

The gas well deliverability equation is often used in productivity evaluation. Houpeurt (1959) proposed a binomial deliverability equation that has been widely used in field deliverability tests. A novel binomial deliverability equation was presented for fractured gas well considering the non-Darcy effect (Wang et al. 2014). Several deliverability models have also been built to consider the stress sensitivity 
effect (Deng et al. 2013; Yang et al. 2008). In addition, a production-prediction model for CBM wells was presented considering the effect of pressure-propagation behavior (Sun et al. 2019). However, these gas deliverability studies are single porosity models. Few studies incorporate the effects of non-Darcy and stress sensitivity into dual-porosity naturally fractured reservoirs (Brohi et al. 2011). Some dualporosity models were proposed to predict well rate behavior (Olarewaju and Lee, 1991; Ramirez et al. 2007; Xue et al. 2020). The Laplace solutions to the semi-analytical models were also presented to predict the vertical or deviated well performance in composite stress-sensitive carbonate gas reservoirs (Zhang et al. 2015; Wang et al. 2017; Meng, 2018; Shi et al. 2018). Nevertheless, it is not convenient to calculate the absolute open flow rate in the field application.

There are several methods developed for gas well reasonable production proration, such as empirical allocation method, productivity index curve method, node analysis method, and numerical simulation method (Zonglin et al. 2006;). The empirical allocation method usually allocates the gas well production according to $1 / 3 \sim 1 / 6$ of the absolute open flow (AOF) rate. The production index curve method considers the turning point from linear trend due to the nonDarcy effect (Lyons and Plisga, 2011). The node analysis method pays more attention to the gas lifting parameters. The numerical simulation method is the most accurate approach for gas well reasonable production proration $(\mathrm{Lu}$ et al. 2017). However, the accuracy of numerical simulation relies on the quality of geologic models and production data. Natural fracture modeling is a challenging task for carbonate reservoirs (Nelson, 2001; Benetatos et al. 2019). Although the multi-porosity model can be used to simulation the carbonate reservoir, dual-porosity model is currently the most popular model that considers the stress sensitivity effect (Chaudhri, 2012; Hinkley et al. 2013).

Few wells of Gaoshiti-Moxi gas reservoir have been conducted deliverability test due to the high cost for ultra-deep wells (>5000 m). The conventional single-point test is not applicable to tight carbonate gas wells (Lei et al. 2017). However, almost all the wells have implemented pressure build-up tests after a period of early production. Hence, transient pressure analysis results can be directly adopted to evaluate gas well deliverability (Rafi and Neil, 1996). In addition, there are not enough data to build the field geologic model to run simulation cases to analyze the proper well production proration. However, the well log, well pressure build-up test, and well production data are enough to build a single-well numerical model to conduct well production proration analysis.

In this paper, a new dual-porosity binomial deliverability model was proposed to consider the effects of non-Darcy and stress sensitivity. The field gas well deliverability test data were used to validate the accuracy of the new analytical model. Then, a single-well numerical model was built on the results of logging, well testing, and production analysis. After the history match, several simulation cases are adopted to analyze the reasonable production proration. Finally, we point out the implications of the new deliverability model and single-well model, and some research points to be conducted in future field development.

\section{Tight carbonate gas well deliverability evaluation}

\section{Conventional binomial deliverability equation}

The typical oil flow follows linear Darcy law, while the gas flow follows the nonlinear Forchheimer law that results from the high-velocity inertial effect. The motion equation with a second proportionality constant could truly describe the high-velocity gas flow (Forchheimer, 1901):

$\frac{d P}{d x}=a v+b v^{2}$

where $v$ is the gas velocity and $P$ is the formation pressure.

A more detailed equation with inertial effect is (Cornell and Katz, 1953)

$\frac{d P}{d x}=\frac{\mu}{K} v+\beta \rho v^{2}$

where $\mu$ is the gas viscosity, $K$ is the formation permeability, $\rho$ is the gas density, $\beta$ is the non-Darcy coefficient.

Based on the above motion equation, a binominal deliverability equation was proposed for vertical gas well productivity evaluation considering the inertial effects around the wellbore (Houpeurt, 1959).

$P_{e}^{2}-P_{w f}^{2}=A q_{s c}+B q_{s c}^{2}$

where $P_{e}$ is the outer boundary pressure, $P_{w f}$ is the bottom hole pressure, $A$ is the linear coefficient, $A=\frac{T \mu Z}{K h}\left(\ln \frac{r_{e}}{r_{w}}+S\right)$, $B$ is the nonlinear coefficient, $B=\frac{\beta \gamma_{g} Z T}{h^{2}}\left(\frac{1}{r_{w}}-\frac{1}{r_{e}}\right)$.

This conventional binomial deliverability equation was widely used for conventional gas reservoir well productivity calculation. The coefficients $A$ and $B$ are usually obtained by linear matching for the rearranged equation, and then, the absolute open flow rate is calculated by

$q_{A O F}=\frac{-A+\sqrt{A^{2}-4 B\left(P_{e}-0.101\right)}}{2 B}$ 


\section{Dual-porosity binomial deliverability equation}

The conventional binomial deliverability equation is obtained for a single porosity reservoir, and it is not suitable for dual-porosity reservoirs such as carbonate gas reservoirs. Firstly, the non-Darcy coefficient correlation was different for tight carbonate gas reservoir. Here a regressed equation was adopted for the Gaoshiti-Moxi gas reservoir (Shusheng et al. 2015).

$\beta=\frac{7.0 \times 10^{9}}{K^{1.42}}$

Secondarily, the stress sensitivity effect is also important for tight carbonate gas reservoirs. Here a matched fracture dynamic permeability equation was used to describe this effect (Shusheng et al. 2015). They proposed a stress-sensitive relationship against crack-type carbonate reservoirs. In their study, the stress-sensitive experiment of typical rock samples of tight carbonate reservoirs was obtained, and three carbonate rock stresses were obtained. To facilitate the application, the stress-sensitive curve is normalized, thereby obtaining a mathematical model of the stress sensitivity of crack-type carbonate rock gas reservoir stress:

$K_{f}=K_{f i}\left(\frac{P_{o b}-P}{P_{o b}-P_{i}}\right)^{-\gamma}$

where $K_{f i}$ is the initial fracture permeability, $P_{i}$ is the initial formation pressure, $P_{o b}$ is the overburden pressure, $\gamma$ is the stress sensitivity coefficient, in this case, $\gamma$ equals 0.6.

A modified pseudo-pressure for stress sensitivity is defined as

$m_{f}^{*}=2 \int_{0}^{P} \frac{P}{\mu Z}\left(\frac{P_{o b}-P}{P_{o b}-P_{i}}\right)^{-\gamma} d P$

The gas radial flow rate is calculated as

$v=\frac{Q_{s c}}{2 \pi r h} \frac{Z P_{s c} T}{P T_{s c}}$

where $Z$ is the gas deviation factor, $P_{s c}$ is the pressure at the surface condition, $T_{s c}$ is the temperature at the surface condition, $P$ is the formation pressure, and $T$ is the formation temperature.

The gas density under reservoir condition is obtained by

$\rho_{g}=\frac{T_{s c} \rho_{g s c}}{P_{s c}} \cdot \frac{P}{T Z}$

where $\rho_{g s c}$ is the gas density at surface normal condition.

Usually $\phi_{f} \ll \phi_{m}, K_{m} \ll K_{f}$, dual-porosity governing equation is $\left\{\begin{array}{c}-\frac{1}{r} \frac{\partial}{\partial r}\left(r \rho_{g} \delta \frac{K_{f}}{\mu} \frac{\partial P_{f}}{\partial r}\right)+\frac{\rho_{g} \alpha K_{m}}{\mu}\left(P_{m}-P_{f}\right)=0 \\ -\frac{\rho_{g} \alpha K_{m}}{\mu}\left(P_{m}-P_{f}\right)=\rho_{g} \phi_{m} C_{m} \frac{\partial P_{m}}{\partial t}\end{array}\right.$

where $r$ is the radius of the reservoir, $\delta$ is the turbulence parameter, $\delta=\frac{1}{1+\frac{\beta \rho K_{f}}{\mu}}, \Phi_{m}$ is the matrix porosity, $C_{m}$ is the matrix compression coefficient, the subscript $m$ represents the matrix system, subscript $f$ represents the fracture system.

Combining Eq. (2) and Eq. (5) (10), a new dual-porosity binomial deliverability equation is obtained.

$m^{*}\left(P_{f e}\right)-m^{*}\left(P_{f w}\right)=A \cdot Q_{s c}+B \cdot Q_{s c}^{2}$

where $A=D\left(\ln \frac{r_{e}}{r_{w}}+S\right)-2 E G\left(r_{e}-r_{w}\right)+\frac{E}{2}\left(r_{e}^{2}-r_{w}^{2}\right)$

$B=\frac{D^{2}}{2 F}\left(\frac{1}{r_{w}}-\frac{1}{r_{e}}\right)-\frac{2 D E G}{F} \ln \frac{r_{e}}{r_{w}}+\left(\frac{D E}{4 F}+\frac{2 E^{2} G^{2}}{F}\right)\left(r_{e}-r_{w}\right)$

$-\frac{E^{2} G}{F}\left(r_{e}^{2}-r_{w}^{2}\right)+\frac{E^{2}}{6 F}\left(r_{e}^{3}-r_{w}^{3}\right)$

$D=\frac{P_{s c} T}{\pi K_{f} h T_{s c}}\left[1-\frac{(1-\omega) r_{w}^{2}}{r_{e}^{2}}\left(1-\frac{2 \bar{\delta}}{\lambda} \ln r_{w}\right)\right], \omega$ is the elastic storativity ratio.

$E=\frac{T P_{s c}(1-\omega)}{\pi K_{f i}\left(r_{e}^{2}-r_{w}^{2}\right) h T_{s c}}$

$F \approx \frac{\bar{\mu} P_{s c} T}{7.0 \times 10^{9} T_{s c} \rho_{g s c} K_{f i}^{0.58}}\left(\frac{P_{o b}-\overline{P_{f}}}{P_{o b}-P_{i}}\right)^{-0.42 \gamma}$

$G=\left(r_{w}^{2} / \lambda\right) \bar{\delta} \frac{\ln \bar{r}}{\bar{r}}, \lambda$ is the inter porosity flow parameter, $\bar{\delta}$ is the average turbulence at the average radius, $\bar{\delta}=\frac{1}{1+\frac{3.5 \times 10^{9} \rho_{g s c} Q_{s c}}{\bar{\mu} \pi h K_{f i}^{0.42}\left(\frac{P_{o b}-\bar{P}_{f}}{P_{o b}-P_{i}}\right)^{-0.42 \gamma}} \text {. }}$.

Then, the absolute open flow can be calculated as

$Q_{A O F}=\frac{-A+\sqrt{A^{2}+4 B\left[m^{*}\left(P_{f e}\right)-m^{*}(0.101)\right]}}{2 B}$

If the reservoir is a two-area composite reservoir, the deliverability equation becomes

$m^{*}\left(P_{f e}\right)-m^{*}\left(P_{f w}\right)=A \cdot Q_{s c}+B \cdot Q_{s c}^{2}$

where $A=A_{1}+A_{2}, B=B_{1}+B_{2}$

$A_{1}=D_{1}\left(\ln \frac{r_{1}}{r_{w}}+S\right)-2 E_{1} G_{1}\left(r_{1}-r_{w}\right)+\frac{E_{1}}{2}\left(r_{1}^{2}-r_{w}^{2}\right)$ 


$$
\begin{aligned}
& A_{2}=D_{2} \ln \frac{r_{e}}{r_{1}}-2 E_{2} G_{2}\left(r_{e}-r_{1}\right)+\frac{E_{2}}{2}\left(r_{e}^{2}-r_{1}^{2}\right) \\
& B_{1}=\frac{D_{1}^{2}}{2 F_{1}}\left(\frac{1}{r_{w}}-\frac{1}{r_{1}}\right)-\frac{2 D_{1} E_{1} G_{1}}{F_{1}} \ln \frac{r_{1}}{r_{w}} \\
& +\left(\frac{D_{1} E_{1}}{4 F_{1}}+\frac{2 E_{1}^{2} G_{1}^{2}}{F_{1}}\right)\left(r_{1}-r_{w}\right) \\
& -\frac{E_{1}^{2} G_{1}}{F_{1}}\left(r_{1}^{2}-r_{w}^{2}\right)+\frac{E_{1}^{2}}{6 F_{1}}\left(r_{1}^{3}-r_{w}^{3}\right) \\
& B_{2}=\frac{D_{2}^{2}}{2 F_{2}}\left(\frac{1}{r_{1}}-\frac{1}{r_{e}}\right)-\frac{2 D_{2} E_{2} G_{2}}{F_{2}} \ln \frac{r_{e}}{r_{1}} \\
& +\left(\frac{D_{2} E_{2}}{4 F_{2}}+\frac{2 E_{2}^{2} G_{2}^{2}}{F_{2}}\right)\left(r_{e}-r_{1}\right) \\
& -\frac{E_{2}^{2} G_{2}}{F_{2}}\left(r_{e}^{2}-r_{1}^{2}\right)+\frac{E_{2}^{2}}{6 F_{2}}\left(r_{e}^{3}-r_{1}^{3}\right) \\
& D_{1}=\frac{P_{s c} T}{\pi K_{f 1 i} h T_{s c}}\left[1-\frac{\left(1-\omega_{1}\right) r_{w}^{2}}{r_{1}^{2}}\left(1-\frac{2 \overline{\delta_{1}}}{\lambda_{1}} \ln r_{w}\right)\right] \\
& D_{2}=\frac{P_{s c} T}{\pi K_{f 2 i} h T_{s c}}\left[1-\frac{\left(1-\omega_{2}\right) r_{1}^{2}}{r_{e}^{2}}\left(1-\frac{2 \overline{\delta_{2}}}{\lambda_{2}} \ln r_{1}\right)\right] \\
& \overline{\delta_{1}}=\frac{1}{1+\frac{3.5 \times 10^{9} \rho_{g s c} Q_{s c}}{\overline{\mu_{1}} \pi h K_{f 1 i}^{0.42}\left(\frac{P_{o b}-\overline{P_{f_{1}}}}{P_{o b}-P_{i}}\right)^{-0.42 \gamma}} \frac{1}{\overline{r_{1}}}} \\
& \overline{\delta_{2}}=\frac{1}{1+\frac{3.5 \times 10^{9} \rho_{g s c} Q_{s c}}{\bar{\mu}_{2} \pi h K_{f 2 i}^{0.42}\left(\frac{P_{o b}-\overline{P_{f 2}}}{P_{o b}-P_{i}}\right)^{-0.42 \gamma}} \frac{1}{\overline{r_{2}}}} \\
& E_{1}=\frac{T P_{s c}\left(1-\omega_{1}\right)}{\pi K_{f 1 i}\left(r_{1}^{2}-r_{w}^{2}\right) h T_{s c}} \\
& E_{2}=\frac{T P_{s c}\left(1-\omega_{2}\right)}{\pi K_{f 2 i}\left(r_{e}^{2}-r_{1}^{2}\right) h T_{s c}} \\
& F_{1}=\frac{\overline{\mu_{1}} P_{s c} T}{7.0 \times 10^{9} T_{s c} \rho_{g s c} K_{f 1 i}^{0.58}}\left(\frac{P_{o b}-\overline{P_{f 1}}}{P_{o b}-P_{i}}\right)^{-0.42 \gamma}
\end{aligned}
$$

$$
\begin{aligned}
F_{2} & =\frac{\overline{\mu_{2}} P_{s c} T}{7.0 \times 10^{9} T_{s c} \rho_{g s c} K_{f 2 i}^{0.58}}\left(\frac{P_{o b}-\overline{P_{f 2}}}{P_{o b}-P_{i}}\right)^{-0.42 \gamma} \\
G_{1} & =\left(r_{w}^{2} / \lambda_{1}\right) \overline{\delta_{1}} \frac{\ln \bar{r}_{1}}{\bar{r}_{1}} \\
G_{2} & =\left(r_{1}^{2} / \lambda_{2}\right) \overline{\delta_{2}} \frac{\ln \bar{r}_{2}}{\bar{r}_{2}}
\end{aligned}
$$

\section{Tight carbonate gas well deliverability evaluation}

Deliverability testing is the most accurate method for well productivity evaluation. It can also be calculated by directly taking the pressure transient analysis results into the deliverability equation. In addition, the single-point method is a widely used empirical equation for well deliverability equation as it only needs one steady test point with the gas flow rate and bottom hole pressure. Here four wells from Gaoshiti-Moxi tight carbonate gas reservoir are chosen for deliverability evaluation. The gas well deliverability results are shown in Table 1.

Based on the comparison for different gas well deliverability evaluation methods (Table 1), it was found that the Mean Absolute Percentage Error (MAPE) of the deliverability equation is as low as $2.15 \%$, and that of one-point is $4.02 \%$ (Fig. 1). The deliverability equation results are close to the deliverability test that shows the new model has high accuracy in gas well deliverability evaluation. It can be also seen that the MAPE of one-point results are distinctly higher than the results of the deliverability equation. That is because the empirical parameter may not be suitable for the fractured carbonate reservoir. The new dual-porosity gas well deliverability model can make a reasonable prediction based on the well build-up test interpretation result, which is a very helpful deliverability method when lacking the deliverability test data.

The deliverability test results are close to the actual well productivity that shows the new model has high accuracy in gas well deliverability evaluation. It can be also seen that one-point results are distinctly smaller than the results of the deliverability test. That is because the empirical parameter may not be suitable for the fractured carbonate reservoir. The new dual-porosity gas well deliverability model can make a reasonable prediction based on the well build-up test interpretation result, which is a very helpful deliverability method when lacking the deliverability test data. 


\section{Tight carbonate gas well reasonable production proration analysis}

At the early stage of gas reservoirs, it is important to set reasonable production proration for each well. After the accurate well deliverability evaluation, the common method is just to use the empirical proportion to guide the gas well production proration. However, there is less theory foundation on how to determine the reasonable proportion parameter. Based on pressure transient analysis, a single-well numerical simulation could accurately describe the well productivity. Here, we take MX22 well as an example to analyze the gas well reasonable production proration.

\section{Tight carbonate single gas well numerical model setup}

MX22 is an early development well in Gaoshiti-Moxi tight carbonate gas reservoir. The production water belongs to condensed water and there is very little water production. Therefore, the gas-water two-phase (water stays under irreducible water state) dual-porosity model is chosen for a single-well simulation study. The model grid dimension

Table 1 Absolute open flow rate comparison for different gas well deliverability evaluation methods

\begin{tabular}{lccc}
\hline Well & $\begin{array}{c}\text { One-point } \\
\left(10^{4} \mathrm{~m}^{3} / \mathrm{d}\right)\end{array}$ & $\begin{array}{l}\text { Deliverability } \\
\text { Eq. }\left(10^{4} \mathrm{~m}^{3} / \mathrm{d}\right)\end{array}$ & $\begin{array}{c}\text { Deliverability } \\
\text { test }\left(10^{4} \mathrm{~m}^{3} / \mathrm{d}\right)\end{array}$ \\
\hline MX22 & 192.50 & 169.31 & - \\
MX105 & 37.36 & 53.33 & 45.51 \\
MX108 & 54.47 & 65.80 & 62.00 \\
GS3 & 152.00 & 154.95 & 158.36 \\
\hline
\end{tabular}

is $74 \times 74 \times 42$. The grid size is $33.81 \mathrm{~m}$ in the horizontal direction. According to the transient pressure analysis, the inner stimulation radius is $98.47 \mathrm{~m}$ and the outer drainage radius is $1412 \mathrm{~m}$. The corresponding square side lengths are $174.53 \mathrm{~m}$ for the inner area and $2502 \mathrm{~m}$ for the outer area. There are three gas-bearing layers and two interlayers. The permeability of gas-bearing layers comes from well testing, and the porosity of gas-bearing layers comes from the well logging average value. The inner and outer area formation property parameters are shown in Table 2 .

The shape factor can be calculated according to the pressure transient analysis. The shape factor of the inner area is

$\alpha_{1}=\frac{\lambda_{1}}{r_{w}^{2}} \frac{K_{f 1 i}}{K_{m 1 i}} \approx 184.4$

The shape factor of the outer area is

$\alpha_{2}=\frac{\lambda_{2}}{r_{w}^{2}} \frac{K_{f 2 i}}{K_{m 1 i}} \approx 0.0466$

The gas component data come from GS3 well gas sample analysis for the same formation as shown in Table 3.

The formation temperature is $152.62{ }^{\circ} \mathrm{C}$. The gas formation volume factor and viscosity are shown in Table 4 under different formation pressure.

According to the MDT water sample analysis from MX22, the water density is $1.0687 \mathrm{~g} / \mathrm{cm}^{3}$. The water formation volume factor is 1.006 under reference pressure $27.85 \mathrm{MPa}$. In addition, the water compressibility coefficient is $4.65 \times 10^{-4} \mathrm{MPa}^{-1}$, and the water viscosity is $0.25 \mathrm{mPa} \bullet \mathrm{s}$ under reservoir conditions. The rock compressibility coefficient is $1.62 \times 10^{-4} \mathrm{MPa}^{-1}$ under $27.85 \mathrm{MPa}$. In order to consider the stress sensitivity, a permeability multiplying factor
Fig. 1 MAPE of different deliverability methods

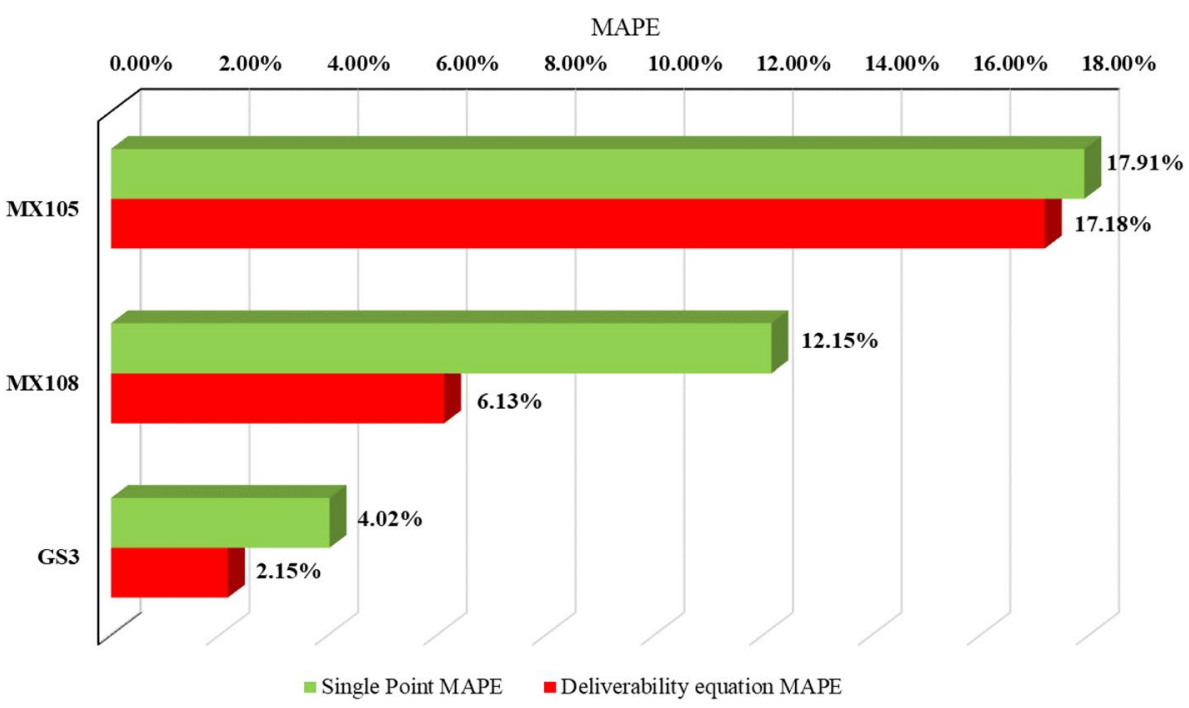


table is achieved by using Eq. (6) with overburden pressure $120 \mathrm{MPa}$ and initial formation pressure $60 \mathrm{MPa}$ (Table 5).

The relative permeability curves come from MX13 well for the same formation core test, which is shown in Fig. 2.

The equilibrium initialization is adopted to get the reservoir reserve. The single-well reservoir reserve is $60.33 \times 10^{8}$ $\mathrm{m}^{3}$, while the single-well control reserve is only $30.7 \times 10^{8}$ $\mathrm{m}^{3}$ from gas rate dynamic analysis. Hence, the pore volume is multiplied by 0.5089 to match the dynamic reserve. The geologic model of MX22 is shown in Fig. 3.

\section{Tight carbonate single gas well history match}

The three gas-bearing layers are perforated for Well MX22. Because of very little water production, MX22 can be seen as a single-phase production vertical well. The well history data have the tubing head pressure, so a VFP table is needed to calculate the vertical tubing flow pressure drop. The VFP table is generated by using the VFPi module for dry gas flow. The tubing inner diameter is $74.6 \mathrm{~mm}$. The tubing of well MX22 is sulfate resistant as there is a hydrogen sulfide component. The tubing roughness is $0.0016 \mathrm{~mm}$, which is much less than that of common tubing. The well bottom hole temperature is $153.51{ }^{\circ} \mathrm{C}$, and the wellhead temperature is $60.2{ }^{\circ} \mathrm{C}$. The formation pressure is $60.4 \mathrm{MPa}$ at the middle gas-bearing layer depth $5453.30 \mathrm{~m}$.

The well MX22 is producing at a constant gas rate, and the formation parameters are adjusted to match the tubing head pressure in the history match process. The tubing head pressure well-matched result is shown in Fig. 3. The inner area permeability is $6.426 \mathrm{mD}$ and the outer area permeability is $0.378 \mathrm{mD}$ after the history match adjusting procedure. The adjusted model is then used for reasonable production proration analysis.

Table 2 Inner and outer area formation property parameters

\begin{tabular}{lllllll}
\hline Area & Layer & \multicolumn{2}{c}{ Porosity } & & \multicolumn{2}{c}{ Permeability $(\mathrm{mD})$} \\
Inner & Dengsi \#1 & 0.0371 & 0.005 & & 0.01 & 3.57 \\
& Dengsi \#2 & 0.0371 & 0.005 & & 0.01 & 3.57 \\
& Dengsi \#3 & 0.0371 & 0.005 & & 0.01 & 3.57 \\
\multirow{4}{*}{ Outer } & Dengsi \#1 & 0.0371 & 0.005 & & 0.001 & 0.21 \\
& Dengsi \#2 & 0.0371 & 0.005 & & 0.001 & 0.21 \\
& Dengsi \#3 & 0.0371 & 0.005 & 0.001 & 0.21 \\
\hline
\end{tabular}

\section{Tight carbonate single gas well reasonable production proration analysis}

Based on the history matched single-well model, the well MX22 stable gas flow rate is obtained under different constant bottom hole pressure. The inflow performance relationship curve of MX22 is shown in Fig. 4. The absolute open flow is about $184.21 \times 10^{4} \mathrm{~m}^{3}$ by extrapolating the inflow performance relationship to the horizontal axis. This can be used for further numerical simulation analysis. In addition, the gas productivity index curve can also be obtained from the simulation results. The horizontal axis is the gas flow rate, while the vertical axis is the square deviation between boundary pressure and bottom hole pressure in the gas productivity index curve. The reasonable gas production rate is the point where the curve deviates from a straight line. The gas productivity index curve of MX22 is illustrated in Fig. 5, and the reasonable gas flow rate is about $26 \times 10^{4} \mathrm{~m}^{3}$ as shown in the turning point. The sand production and bottom water are not considered when analyzing the production proration. The other only limiting condition is the lowest gas transportation pressure that is $2 \mathrm{MPa}$ here. The corresponding highest gas flow rate is $123.464 \times 10^{4} \mathrm{~m}^{3}$ by conducting a simulation case with a $2 \mathrm{MPa}$ tubing head pressure limit (Fig. 6).

In order to find the reasonable proportion of the absolute open flow rate, five cases are designed to compare the

Table 4 Gas PVT under different pressures

\begin{tabular}{llll}
\hline Pressure $\mathrm{m}(\mathrm{MPa})$ & Z-factor & Volume factor & Viscosity $(\mathrm{mPa} \bullet \mathrm{s})$ \\
\hline 0.101 & 0.99797 & 1.4548 & 0.014043 \\
5.0 & 0.98077 & 0.0289 & 0.014770 \\
10.0 & 0.97033 & 0.0143 & 0.015632 \\
15.0 & 0.97683 & 0.0096 & 0.016671 \\
20.0 & 0.98019 & 0.0072 & 0.017963 \\
25.0 & 0.99356 & 0.0059 & 0.019603 \\
30.0 & 0.99146 & 0.0049 & 0.021723 \\
35.0 & 1.03400 & 0.0043 & 0.024505 \\
40.0 & 1.07655 & 0.0040 & 0.028212 \\
45.0 & 1.11910 & 0.0037 & 0.033233 \\
50.0 & 1.16165 & 0.0034 & 0.040155 \\
55.0 & 1.20419 & 0.0032 & 0.049894 \\
60.0 & 1.24674 & 0.0031 & 0.063916 \\
0.101 & 0.99797 & 1.4548 & 0.014043 \\
\hline
\end{tabular}

Table 3 Gas component analysis of GS3 well

\begin{tabular}{lllllllll}
\hline $\mathrm{CH}_{4}(\%)$ & $\mathrm{C}_{2} \mathrm{H}_{6}(\%)$ & $\mathrm{H}_{2} \mathrm{~S}(\%)$ & $\mathrm{CO}_{2}(\%)$ & $\mathrm{N}_{2}(\%)$ & Molecular weight & Relative density & $\begin{array}{l}\text { Pseudo-critical tempera- } \\
\text { ture (K) }\end{array}$ & $\begin{array}{l}\text { Pseudo-critical pressure } \\
(\mathrm{MPa})\end{array}$ \\
\hline 91.68 & 0.04 & 1.58 & 6.55 & 0.13 & 18.178 & 0.6287 & 192.8241 & 4.8458 \\
\hline
\end{tabular}


Table 5 Permeability multiplying factor under different pressures

\begin{tabular}{llllllll}
\hline Pressure (MPa) & 5 & 15 & 25 & 35 & 45 & 55 & 60.4 \\
\hline Multiply factor & 0.6741 & 0.7119 & 0.7560 & 0.8082 & 0.8712 & 0.9493 & 1.000 \\
\hline
\end{tabular}

\section{Discussion}

The absolute open flow rates of the new gas well deliverability equation are more accurate than those of the single-point method as shown in Table 1 . The results of the new deliverability equation are higher than those of the deliverability test for some wells such as MX 108 and MX105. However, the result of the new deliverability equation is lower than that of the deliverability test for GS3. This abnormal phenomenon shows that the new gas well deliverability equation may have some bias in absolute open flow rate evaluation. On the one side, this may result from deliverability test inaccuracy such as abnormal data from instrumental error. On the other side, this may result from the inaccuracy of transient pressure analysis such as unreasonable interpretation. In other words, the new workflow based on the well build-up test interpretation result has two sides. It can make a reasonable prediction when the deliverability test data lacks. The accuracy of the new equation relies on the accuracy of the pressure transient analysis. In addition, the absolute open flow from the numerical simulation is higher than that from the new deliverability equation, which also shows that the pressure transient analysis has some deviation in formation property prediction as the numerical simulation modified the permeability for history match. It is suitable to comprehensively utilize the above methods in tight carbonate gas well deliverability evaluation.

The single-well simulation could predict the cumulative gas production under different allocating gas rates as shown in Fig. 7. The turning point $1 / 6\left(30.70 \times 10^{4} \mathrm{~m}^{3}\right)$ may be the

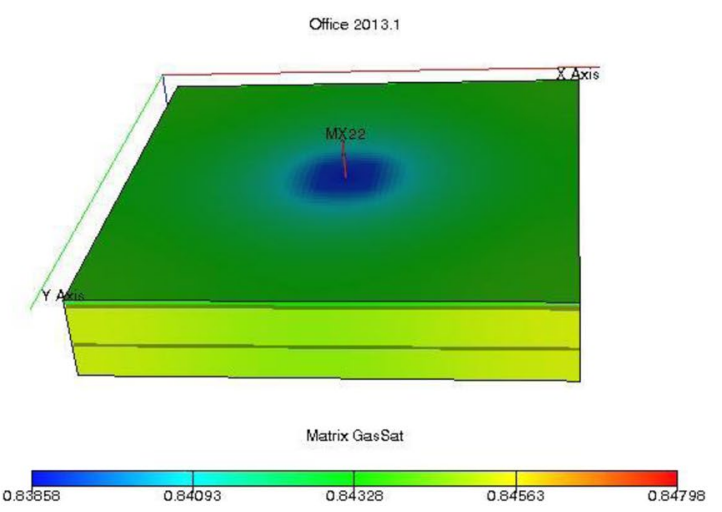

(b)

(a)

Fig. 3 MX22 single-well geologic model: a fracture permeability of the inner area and the outer area; $\mathbf{b}$ initial matrix gas saturation distribution

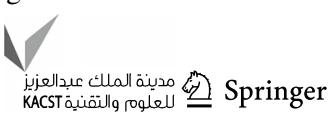


Fig. 4 Tubing head pressure matched result for MX22 well

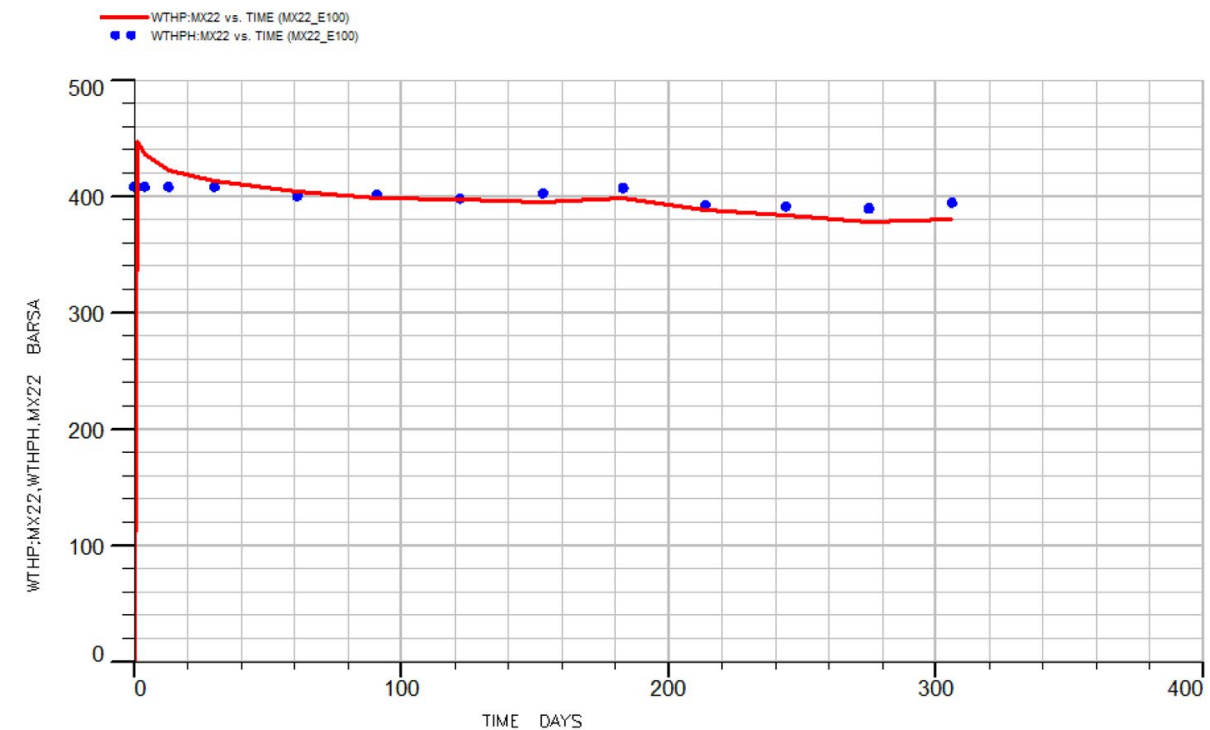

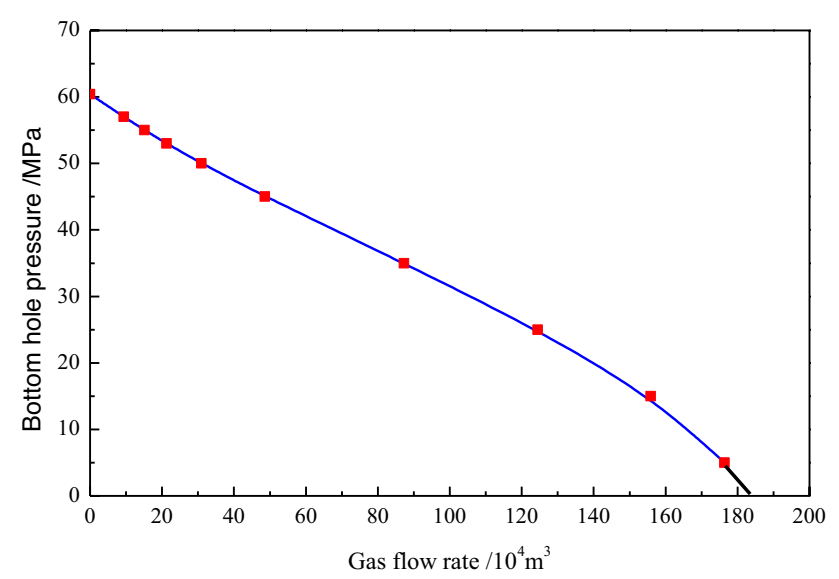

Fig. 5 Inflow performance relationship curve of MX22 well

reasonable allocation proportion for MX22 which indicates that $1 / 6$ may be suitable for high productivity gas well proration. The stable production period for $1 / 6$ is 210 months that are also acceptable for actual well management. It should be mentioned that the tight carbonate gas reservoir has few sandstone production problems. The water production is not involved at the early stage; however, the bottom or edge water has a huge effect on gas production. Similarly, the stress sensitivity effect has a small influence at the early production stage and a great effect on the well productivity at the later production stage. What is more, the core test stress sensitivity parameters may not suitable for actual well production performance.

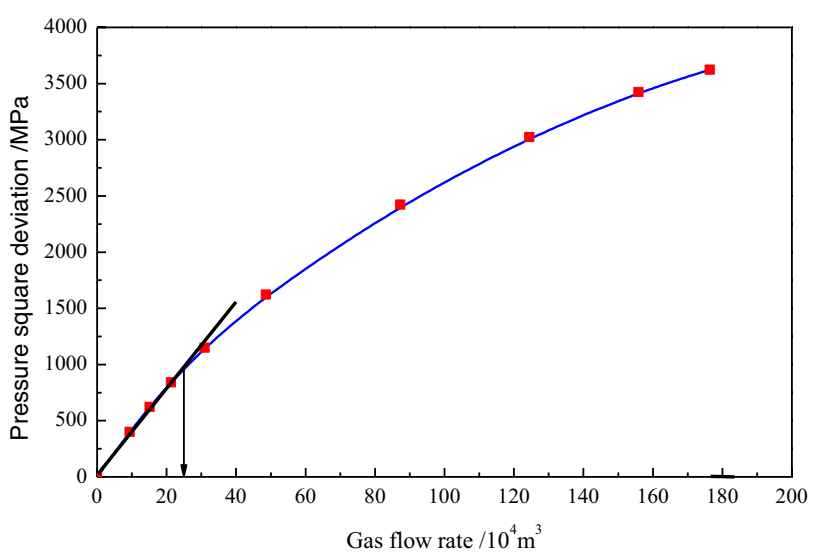

Fig. 6 Gas well productivity index curve of MX22 well

The new gas deliverability equation and the single-well numerical simulation may be helpful at the early gas production evaluation and proration. As the production goes on, some research should be suggested to conduct in future. Firstly, the new model for deviated wells or horizontal wells should be studied in future. The vertical wells are commonly used at the early stage; however, deviated or horizontal wells are widely used at the development adjustment stage. Secondarily, edge water or bottom water must be considered in future reservoir management. Actually, there is bottom water under the main gas-bearing layers and the water channeling or invasion will hugely damage the gas well production. Hence, new two-phase deliverability equation and whole field simulation model are needed for water encroachment evaluation and production optimization. At last, the stress sensitivity effect should be carefully evaluated by combing lab core tests and field dynamic data analysis, which should also be considered in the field development plan in future. 
Fig. 7 Stable production period under different allocating gas rates of MX22 well

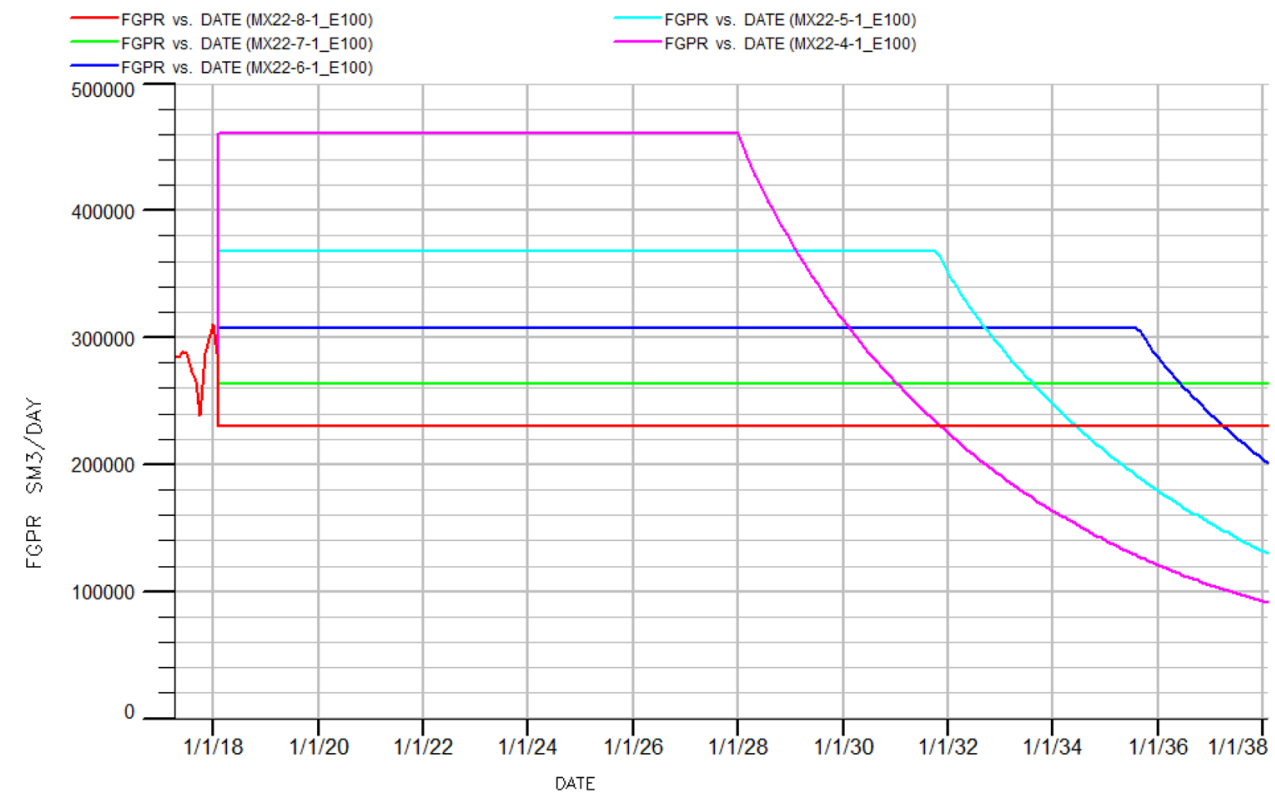

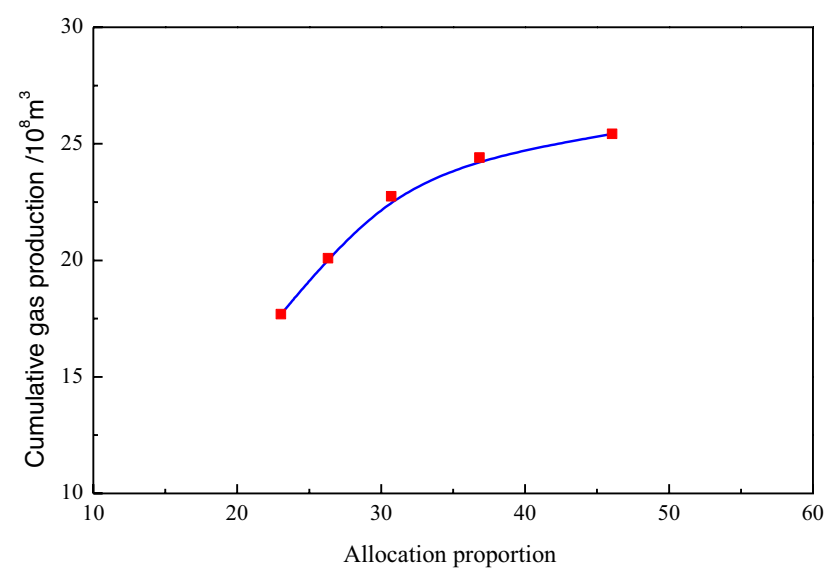

Fig. 8 Cumulative gas production under different allocating gas rates of MX22 well

\section{Conclusions}

1. The conventional binomial deliverability equation is not suitable for dual-porosity gas well productivity evaluation. A new dual-porosity binomial deliverability equation was developed with considering both the non-Darcy and the stress sensitivity effects. The field well deliverability calculation cases validated the reasonableness.

2. The empirical one-point method may not be suitable for the fractured carbonate gas reservoir deliverability evaluation. The new dual-porosity tight carbonate gas well deliverability model can make a reasonable prediction based on the well build-up test interpretation result, which is a very helpful deliverability method when lacking deliverability test.

3. The geological model was built on the results of logging, well testing, and production analysis. A VFP table was generated to consider the pressure drop during the flow in vertical tubing, which should carefully choose the toughness according to the tubing type. A reasonable production proration analysis can be conducted based on history matched single-well model.

4. The gas productivity index curve of MX22 was obtained after several simulation cases, and five cases were designed to compare the stable production period and cumulative gas production. The turning point $1 / 6$ $\left(30.70 \times 10^{4} \mathrm{~m}^{3}\right)$ may be the reasonable allocation proportion for MX22 which indicates that 1/6 may be suitable for high productivity gas well proration.

\section{Appendix A}

The derivation process of the new dual-porosity binomial deliverability equation.

The derivation process from Eq. 11 is shown here.

Using the first equation of Eq. 10, we can obtain differential equation of fracture system

$C_{0} \xi \frac{\partial}{\partial t}\left[-\frac{1}{r} \frac{\partial}{\partial r}\left(\delta r \frac{\partial m_{f}}{\partial r}\right)\right]+\frac{K_{f}}{\mu}\left[-\frac{1}{r} \frac{\partial}{\partial r}\left(\delta r \frac{\partial m_{f}}{\partial r}\right)\right]=C_{0} \frac{\partial m_{f}}{\partial t}$

where $C_{0}=\phi_{m} C_{m}, \xi=\frac{\alpha K_{f}}{K_{m}}=\frac{r_{w}^{2}}{\lambda}, \lambda=\frac{\alpha r_{w}^{2} K_{m}}{K_{i}}$.

If the crossflow is not large, the fracture control equation can be rewritten as 
$\frac{\xi}{\eta} \frac{\partial}{\partial r}\left[-\frac{1}{r} \frac{\partial}{\partial r}\left(r \delta \frac{\partial m_{f}}{\partial t}\right)\right]-\frac{1}{r} \frac{\partial}{\partial r}\left(\delta r \frac{\partial m_{f}}{\partial r}\right)=\frac{1}{\eta} \frac{\partial m_{f}}{\partial t}$

where $\eta$ is pressure coefficient, $\eta=\frac{K_{f}}{\mu \phi_{m} C_{m}}$.

Using the pseudo-pressure function and material balance equation, we can obtain

$\frac{\partial m_{f}}{\partial t}=\frac{2 P_{f}}{\mu Z} \frac{\partial P_{f}}{\partial t}=-\frac{2 T P_{s c}}{\left(\left(\phi C_{t}\right)_{f}+\left(\phi C_{t}\right)_{m}\right) \mu \pi\left(r_{e}^{2}-r_{w}^{2}\right) h T_{s c}} Q_{s c}$

Using average turbulence coefficient, separation variables and integral, we can obtain

$r \delta \frac{\partial m_{f}}{\partial r}=2 E Q_{s c}\left(\frac{r^{2}}{2}-\frac{r_{w}^{2} \bar{\delta}}{\lambda} \ln r\right)+C$

where $E=\frac{T P_{s c}(1-\omega)}{\pi K_{f}\left(r_{e}^{2}-r_{w}^{2}\right) h T_{s c}}, C$ is integration constant.

Using the inner boundary conditions, we can obtain

$C=\frac{P_{s c} T}{\pi K_{f} h T_{s c}}\left[1-\frac{(1-\omega) r_{w}^{2}}{r_{e}^{2}}\left(1-\frac{2 \bar{\delta}}{\lambda} \ln r_{w}\right)\right] Q_{s c}$

Using internal boundary conditions and the definition of the seepage speed, we can obtain

$$
\begin{aligned}
\frac{\partial m_{f}}{\partial r}= & \frac{D^{2} Q_{s c}^{2}}{2 F} \frac{1}{r^{2}}+\left(D Q_{s c}-\frac{2 D E G}{F} Q_{s c}^{2}\right) \frac{1}{r} \\
& +\left(\frac{D E}{4 F} Q_{s c}^{2}-2 E G Q_{s c}+\frac{2 E^{2} G^{2}}{F} Q_{s c}^{2}\right) \\
& +\left(E Q_{s c}-\frac{2 E^{2} G}{F} Q_{s c}^{2}\right) r+\frac{E^{2} Q_{s c}^{2}}{2 F} r^{2}
\end{aligned}
$$

where $D=\frac{P_{s c} T}{\pi K_{f} h T_{s c}}\left[1-\frac{(1-\omega) r_{w}^{2}}{r_{e}^{2}}\left(1-\frac{2 \bar{\delta}}{\lambda} \ln r_{w}\right)\right], F=\frac{\mu P_{f}}{K_{f}^{2} \beta \rho Z}$, $G=\left(r_{w}^{2} / \lambda\right) \bar{\delta} \frac{\ln \bar{r}}{\bar{r}}$.

Separating the variables and integral to the above formula, a new dual-porosity binomial deliverability equation is obtained as

$m\left(P_{f e}\right)-m\left(P_{f w}\right)=A \cdot Q_{s c}+B \cdot Q_{s c}^{2}$

Funding This research was mainly funded by the Open Fund of State Key Laboratory of Oil and Gas Reservoir Geology and Exploitation (Chengdu University of Technology) grant number PLC 20180705. Some support came from Sichuan Province Education Department (grant number 18ZB0072). This work was also partly sponsored by the National Natural Science Foundation of China (grant number 51804048). Many thanks are indebted to PetroChina Southwest Oil\&Gas Field Company to permit the paper publication and supply the Field data and Eclipse software. In addition, thank the anonymous reviewers' comments for the paper revision.

\section{Declarations}

Conflict of interest The authors declare that they have no conflict of interest.

Ethical approval I certify that this manuscript is original and has not been published and will not be submitted elsewhere for publication while being considered by the Journal of Petroleum Exploration and Production Technology. And the study is not split up into several parts to increase the quantity of submissions and submitted to various journals or one journal over time.

Open Access This article is licensed under a Creative Commons Attribution 4.0 International License, which permits use, sharing, adaptation, distribution and reproduction in any medium or format, as long as you give appropriate credit to the original author(s) and the source, provide a link to the Creative Commons licence, and indicate if changes were made. The images or other third party material in this article are included in the article's Creative Commons licence, unless indicated otherwise in a credit line to the material. If material is not included in the article's Creative Commons licence and your intended use is not permitted by statutory regulation or exceeds the permitted use, you will need to obtain permission directly from the copyright holder. To view a copy of this licence, visit http://creativecommons.org/licenses/by/4.0/.

\section{References}

Benetatos C, Giglio G (2019) Coping with uncertainties through an automated workflow for 3D reservoir modelling of carbonate reservoirs. Geosci Front. https://doi.org/10.1016/j.gsf.2019.11.00

Brohi, I., Pooladi-Darvish, M., and Roberto A.. Modeling Fractured Horizontal Wells As Dual Porosity Composite Reservoirs Application to Tight Gas, Shale Gas and Tight Oil Cases. Paper presented at the SPE Western North American Region Meeting, Anchorage, Alaska, USA, May 2011

Chaudhri, MM. Numerical Modeling of Multi-Fracture Horizontal Well for Uncertainty Analysis and History Matching: Case Studies from Oklahoma and Texas Shale Gas Wells. Paper presented at the SPE Western Regional Meeting, Bakersfield, California, USA, March 2012.

Cho Y, Ozkan E, Apaydin OG (2013) Pressure-dependent natural-fracture permeability in shale and its effect on shale-gas well production. SPE Reservoir Eval Eng 16(02):216-228

Cornell D, Katz DL (1953) Flow of gases through consolidated porous media. Ind Eng Chem 45(10):2145-2152

Deng J et al (2013) Productivity prediction model of shale gas considering stress sensitivity. Natural Gas Geoscience 24.3:456-460-638

Feng X, Peng X, Li L et al (2019) Influence of reservoir heterogeneity on water invasion differentiation in carbonate gas reservoirs. Natural Gas Industry B 6(1):7-15

Forchheimer P (1901) Wasserbewegung durch boden. Z. Ver. Deutsch, Ing 45:1782-1788

Hinkley, R, Gu, Z, Wong, T, et al. Multi-Porosity Simulation of Unconventional Reservoirs. Paper presented at the SPE Unconventional Resources Conference Canada, Calgary, Alberta, Canada, November 2013

Houpeurt A (1959) On the flow of gases in porous media. Revue De L'institut Francais Du Petrole 14(11):1468-1684

Jia A et al (2017) Technical measures of deliverability enhancement for mature gas fields: a case study of Carboniferous reservoirs in Wubaiti gas field, eastern Sichuan Basin. SW China Petrol Explor Develop 44(4):615-624 
Lei H et al. (2017) A new method for calculating single-point productivity equation coefficient $\alpha$ in heterogeneous gas reservoir, IOP Conference Series: Earth and Environmental Science, pp. 012035

Lu W, Shenglai Y, Yicheng L et al (2017) Experiments on gas supply capability of commingled production in a fracture-cavity carbonate gas reservoir. Pet Explor Dev 44(5):824-833

Lyons WC, Plisga GJ (2011) Standard handbook of petroleum and natural gas engineering. Elsevier

Meng F et al (2018) Production performance analysis for deviated wells in composite carbonate gas reservoirs. J Nat Gas Sci Eng $56: 333-343$

Nelson R (2001) Geologic analysis of naturally fractured reservoirs. Elsevier

Olarewaju JS, Lee WJ (1991) Rate behavior of composite dual-porosity reservoirs. Servicio de Publicaciones, 203-208

Pedrosa Jr OA (1986) Pressure transient response in stress-sensitive formations, SPE California Regional Meeting. Society of Petroleum Engineers

Pereira CA, Kazemi H, Ozkan E (2006) Combined effect of nonDarcy flow and formation damage on gas well performance of dual-porosity and dual-permeability reservoirs. SPE Res Eval Eng 9(05):543-552

Rafi AH, Neil H (1996) Reservoir management: principles and practices. J Petrol Technol 48(12):1129-1135

Ramirez BA, Kazemi H, Ozkan E, Al-Matrook MF (2007) Non-Darcy flow effects in dual-porosity, dual-permeability naturally fractured gas condensate reservoirs, SPE Annual Technical Conference and Exhibition. Society of Petroleum Engineers

Shi J, Wang S, Xu X et al (2018) A semianalytical productivity model for a vertically fractured well with arbitrary fracture length under complex boundary conditions. SPE J 23(06):2080-2102

Shusheng G, Huaxun L, Dong R (2015) Deliverability equation of fracture-cave carbonate reservoirs and its influential factors. Nat Gas Ind 35(9):48-54

Smith MB et al. (2004) An investigation of non-darcy flow effects on hydraulic fractured oil and gas well performance, Spe technical conference and exhibition Houston, Texas
Sun Z, Shi J, Wu K et al (2019) Effect of pressure-propagation behavior on production performance: implication for advancing lowpermeability coalbed-methane recovery. SPE J 24(02):681-697

Tan Q, Kang Y, You L et al (2021) Stress-sensitivity mechanisms and its controlling factors of saline-lacustrine fractured tight carbonate reservoir. J Nat Gas Sci Eng 88:103864

Wang C, Li ZP, Lai FP (2014) A novel binomial deliverability equation for fractured gas well considering non-Darcy effects. J Nat Gas Sci Eng 20(2):27-37

Wang H, Ran Q, Liao X (2017) Pressure transient responses study on the hydraulic volume fracturing vertical well in stress-sensitive tight hydrocarbon reservoirs. Int J Hyd Energy. https://doi.org/ 10.1016/j.ijhydene.2017.04.143

Wei $\mathrm{G}$ et al (2015) Characteristics and accumulation modes of large gas reservoirs in Sinian-Cambrian of Gaoshiti-Moxi region. Sichuan Basin Acta Petrolei Sinica 36(1):1-12

Xue Y, Teng T, Dang F et al (2020) Productivity analysis of fractured wells in reservoir of hydrogen and carbon based on dual-porosity medium model. Int J Hyd Energy 45(39):20240-20249

Yang B, Jiang HQ, Chen MF, Ning B, Fang Y (2008) Diliverability equation for stress-sensitive gas reservoir. J Southwest Petrol Univ.

Zonglin Z, Zhengjun Z, Qi Z, Qingfeng S, Tiezhu T (2006) Jingbian gasfield well productivity verification \& proper production proration. Nat Gas Ind 26(9):106

Zhang Q, Su Y, Wang W et al (2015) A new semi-analytical model for simulating the effectively stimulated volume of fractured wells in tight reservoirs. J Nat Gas Sci Eng 27:1834-1845

Publisher's Note Springer Nature remains neutral with regard to jurisdictional claims in published maps and institutional affiliations. 